This is a self-archived version of an original article. This version may differ from the original in pagination and typographic details.

Author(s): Lyytinen, Heikki; Richardson, Ulla; Aro, Mikko

Title: Developmental Dyslexia in Finnish

Year: 2019

Version: Accepted version (Final draft)

Copyright: (c) Cambridge University Press 2019

Rights: In Copyright

Rights url: http://rightsstatements.org/page//nC/1.0/?language=en

Please cite the original version:

Lyytinen, H., Richardson, U., \& Aro, M. (2019). Developmental Dyslexia in Finnish. In L. Verhoeven, C. Perfetti, \& K. Pugh (Eds.), Developmental Dyslexia across Languages and Writing Systems (pp. 118-132). Cambridge University Press.

https://doi.org/10.1017/9781108553377.006 


\title{
Developmental Dyslexia in Finnish
}

\author{
Heikki Lyytinen, Ulla Richardson, and Mikko Aro \\ University of Jyväskylä
}

\section{Introduction}

Written Finnish and the Finnish literacy culture provide an exceptional context for an interesting division into various processes associated with reading acquisition. The orthography of Finnish is relatively optimally wired for giving young learners an easy time to acquire basic decoding skills. Finnish orthography has full transparency in both reading and writing directions. After learning the limited set of sounds connected consistently with specific graphemes, learners usually learn to decode accurately, even those with learning difficulties in reading.

The high status of literacy in Finland, from the early stages of its writing system, has led to additional benefits. From the beginning of the written language, people were encouraged to learn to read, because they were given a permission to marry only if they were able to read Luther's Small Catechism. This was one of the central factors that attracted people to learn reading skills. Prior to this, the use of writing was restricted to the learned and members of high social status. In contrast today, reading is universal in Finland and there are practically no illiterates.

The high status of literacy in Finnish is related also to the general use of a standardized spoken language form. This standard form clearly differs from the typical colloquial speech specifically in its more complex syntactical forms. In general, speakers can use the standard form or at least a modified version of it, and experience it in formal communication situations including television and radio (even in children's programs), public speeches and in schools. In turn, the standard Finnish follows closely the established written form of the language. In fact, one of the specific duties of the Institute for the Languages of Finland is to provide guidance for the correct use of the standard Finnish including the written language forms, and people are compliant to these 
guidelines. The dominance of the standard language form in the written text is obvious since almost all published texts (including subtitles on foreign TV programs) use the standard language form instead of colloquial expressions. There is no reason why the colloquial expressions could not be used in a written format since these expressions also can be written using the consistent graphemephoneme correspondence rules. However, currently the colloquial expressions are used in a written format mainly for personal communication, especially by the younger generations of Finnish speakers. Thus, learners are usually well accustomed to the written text form (standard Finnish) that represents the standard spoken language still used widely in the Finnish society. This in turn facilitates learning the main point of decoding skills that is the connection between spoken language units to the corresponding written language units.

In such writing context the learning burden required for accurate decoding skill is low. Following optimal instruction in the basics of reading, learning to read is a matter of practice on 24 letter-sound connections (occurring in Finnish words) and the ordered assembly of the sounds into words. But even in such a system, some children struggle. More than $20 \%$ of Finnish children get remedial support in the school in an organized way. That some children need more time to learn is understood as a natural phenomenon. This has meant that dyslexia has not received a very visible role in nomenclature used by Finnish educators (nor medical experts). In fact, it was only very recently (in the year 2006) when individuals who continue to struggle with reading and writing were officially granted special arrangements in matriculation examination, which is a national exam at the end of high school.

Compromised reading in the Finnish context (and in any transparent orthography) tends to mean difficulties becoming sufficiently fluent so that cognitive/memory resources are spared comprehending long and difficult written sentences. Struggling readers focus their attention on single letters and are unable to read with the fluency needed for learning. It has been observed (PIAAC 2012, see Malin, Sulkunen, \& Laine, 2013, p.38) that even today around 370,000 Finnish 
adults are not fully literate. They do not comprehend what they read at an expected level. The most likely reason is that they have not continued practicing reading after school.

\section{Learning to Read Finnish}

\subsection{Finnish Language and Its Orthography}

The Finnish language does not belong to the Indo-European languages, but to the small FennoUgric language family. The basic Finnish vocabulary is quite distinct as compared to major European languages, although there are a large number of loan words, both old and more recent, from especially Germanic and Baltic languages. It is different from the more prominent languages of reading research with respect to its morphology and orthographic transparency. Thus, Finnish offers an interesting contrast to especially English, in revealing universal and more languagespecific aspects of reading acquisition and its problems. Here, we aim to describe briefly the basic aspects of linguistic and writing systems of Finnish, as well as the basic findings concerning reading acquisition (for more details on the topic, see Aro, in press).

Finnish has 8 vowel sounds and 13 native consonant sounds. In addition are three consonant sounds that are used in recent loan words only. Finnish also has many diphthongs that combine two distinct vowel sounds. The vowel harmony means that there can be only either front or back vowels in a word, and this affects also endings. One important feature of the Finnish phonological system is that all vowels and most consonants can have two lengths: short and long. The length distinction affects meaning, and the length of vowels and consonants can vary independently. This means that words like tuli [fire], tuuli [wind], and tulli [customs] differ only with respect to phoneme lengths. The syllable structure is relatively simple, with a lot of open syllables. Consonant clusters are rare, and exist in initial position only in recent loan words.

The Finnish morphology is agglutinative and relatively complex. Nouns, adjectives, verbs, numerals, and pronouns are inflected based on their grammatical role within the sentence, and the words can have several affixes. For example, nouns can have fifteen cases expressed with 
inflections, and on top of that possessive suffixes and various clitics. Thus, a single word can carry a lot of morphological information. For example, a question like "Would you believe?" can be expressed as "Uskoisitko?" in Finnish. A noun can have over 2000 different forms depending on the inflections and this number is even higher for verbs. On top of rich inflectional system, the use of derivative suffixes is common in word formation, and compounding is frequent. From the point of view of reading, this means that words with one morpheme are less common in texts than words with several morphemes.

Finnish is written with 26 letters of the Latin alphabet, with the addition of $\langle\ddot{a}>,<a ̊>$, and $<\ddot{o}>$. All Finnish phonemes have a distinct corresponding grapheme, with the exception of /ng/, that is marked with the letter $\langle\mathrm{n}(+\mathrm{k})\rangle$ and with a digraph $\langle\mathrm{ng}\rangle$ as a long sound. The long phonemic sound is in all other cases systematically marked in writing by doubling the corresponding letter. Thus, although the morphological system is complex, the orthography reflects a rather strict phonemic principle. Each letter represents reliably a single sound, and each phoneme is represented reliably with a corresponding letter, independent of the context. The words in a text tend to be long (averaging between 7 and 8 letters), due to compounding, derivations, and inflections.

\subsection{Challenges in Learning to Read Finnish}

For the learner, the orthographic principle is easy to master, and phonemic assembly on the level of single letters is sufficient for decoding. The challenges for decoding (and spelling) relate to marking the length of the phoneme and long words. Correspondingly, early instruction of reading and spelling emphasize syllable as a sub-stage in decoding, and syllables are marked with hyphens in early reading materials. Due to the transparency of the orthography, most children acquire the basic decoding skill rather effortlessly and often with fairly little instructional support. Around one third of children are able to decode already at school entry, and typically, close to perfect reading accuracy is reached quite early. The individual differences in reading skill are reflected mostly in 
reading speed, although children struggling with reading make also more errors in reading and especially spelling as compared to typically developing peers. Reading instruction is based on synthetic phonics, and attempts at reading are based rather uniformly on decoding; there are no indications of a logographic stage in reading development. The correlation between word and pseudoword reading in the early years of reading development is reported as close to perfect. Since grapheme-phoneme correspondences are regular and symmetrical, spelling instruction starts hand in hand with reading instruction, and typically early spelling development closely follows development in reading.

The studies focusing on development of phonological awareness have indicated development from large (syllables) to small (phonemes) units. The awareness of phonemes seems intertwined with letter knowledge and early reading skills, since the orthography is transparent at the level of single-letter graphemes and the letter names consistently include the letter sounds. The role of morphological awareness in reading development is still largely unstudied. That is a direction of research that is interesting especially from the point of fluency development, the stage after acquisition of basic accurate decoding skill.

\section{Reading Difficulties in Finnish}

\subsection{Historical and Cultural context}

Soon after Finnish orthography was defined by Bishop Agricola (1510-1557, his ABC-book was published in 1543) following carefully the Latin model, the religious authorities invented an effective way to motivate people to learn to read. To be approved to marry according to the Christian custom in Finland, people had to learn the Vähä katekismus, the Small Catechism (published in Finnish in 1529, which contained the core Lutheran religious messages. Motivation for reading continues to be high in modern Finland. If we ask children who are entering school what 
they wanted to learn there, most of them mention reading as the most important target. More than a third of Finnish children have learned to read before they enter school at the age of 7.

\subsection{Identification and Prevalence of Dyslexia}

In the Finnish school system formal diagnosis of disability is not required for having extra support at school. The support for learning is built on three levels (general, intensified, and specific support) with the individualization, intensity, means of support, and involvement of special education teachers increasing with the levels. The need for support is assessed by the teachers, and the means of support are decided in cooperation of the teachers involved. In more severe cases of learning problems, multidisciplinary expertise is involved in planning and follow-up, including psychologists or physicians. Typically, dyslexic problems are dealt with within the school context. In every Finnish school special educational support is available. For dyslexia, support is carried out typically at the levels of general or intensified support in the form of part-time special education. This means that the child has one or more lessons per week either individually or in a small group with a special education teacher. More than one fifth of the children at grade levels 1 to 9 receive part-time special education at some point of the school year, this figure being highest for children in the first two grades (Official Statistics of Finland, 2014).

Typically, children struggling with the skill development are identified early. The special education teachers screen the children for poor reading skills, letter knowledge, and relevant prereading skills at school entry. On the basis of screening results, the need for extra support is evaluated, and it is typically offered in the form of part-time special education. The first months of reading instruction might also be carried out in flexible groups, where special education teacher is responsible for teaching the children that seem most at-risk for problems in skill development. Also, co-teaching is becoming more common. At later grade levels, the reading problems are generally supported via part-time special education and individualized pedagogical arrangements in various learning situations, like tests. 
A formal medical diagnosis of dyslexia in children is quite rare, mainly given to children who have encountered medical professionals due to especially severe or comorbid problems. It is clear, however, that the prevalence of developmental reading problems, dyslexia, is unrelated to the diagnostic practices. The prevalence estimates are always dependent on the criteria used, but also on the level of skill that is considered age-appropriate. The early curriculum is more or less based on the assumption that children acquire the ability for independent reading during the first school year, or at the latest, second grade. From third grade on the schoolchildren are expected to use reading skill fluently to meet the demand of school subjects and longer texts. Although it is hard to give an objective estimate of the prevalence of dyslexia, it is safe to assume that it does not differ markedly from other languages. Reading accuracy in Finnish generally develops rather quickly after early reading instruction and even children struggling with decoding master it during the first or second grade. Dyslexic children, however, have long lasting and marked problems in reading speed and sometimes also in spelling accuracy. Thus, also the tests used for identification of reading problems are typically measures of reading efficiency, combining accuracy and speed in the test score.

While the majority of dyslexic children do not get support outside the school setting, the children can be referred to assessments of school psychologists who are available mostly in cities and large rural municipalities, or psychologists at family guidance centers of the municipalities. This consultation is used for planning and tailoring the support that is built within the school and classroom setting.

\section{Behavioral and Neurocognitive Evidence}

The development of readiness to learn to read has been examined in detail in the Jyväskylä Longitudinal study of Dyslexia (JLD, for the most recent review of results, see Lyytinen, Erskine, Hämäläinen, Torppa, \& Ronimus, 2015). This study of children at familial risk for dyslexia has now followed one hundred individuals at risk from birth to puberty along with a comparable group of 
individuals without risk. The earliest predictive signs of dyslexia were observed at age of 3 to 5 days using brain event-related potentials to both sinusoidal sounds (Leppänen et al., 2010) and syllables (da-ba-ga; Guttorm, Leppänen, Hämäläinen, Eklund, \& Lyytinen, 2010). Both studies revealed ERP-features which had significant correlations to reading acquisition. Surprisingly the significant prediction was observed not only from responses to speech sounds but also the so-called mismatch (MMN) response to pitch differences. ERPs to syllables differed between risk and non-risk groups at that very early age and these differences had significant predictive correlations to a large number of reading-related measures years later. These are pure empirical predictions that show that something in the brain's activity reflected in processing sounds behaves differently depending on the occurrence of dyslexia, which obviously is only observable later on when children attempt to learn to read.

To have some understanding how this may happen, we consider another discovery: that speech perception of phonemic duration was compromised from the very beginning. It is the most distinctive feature of dyslexia in Finnish observable in the spelling of almost all children with dyslexia at reading age. Most Finnish phonemes can occur in short and long form and this is also reflected in the writing: the short phonemes are written with one letter but long phonemes are written with two identical letters. Infants become sensitive to perceive these from very early age. We observed (Richardson, Leppänen, Leiwo, \& Lyytinen, 2003) that at 6 months, categorical perception of phonemic length (measured through head turn conditioning) reveals differences between children with and without familial risk. The risk children need longer silence in the context of the $t$-consonant to perceive it as long as the non-risk children.

Thus, it appears that the brain of the children with genetic predisposition to dyslexia does not respond to language input in the same way as typical children. These children may fail to perceive the distinctive features of speech that differentiate among similar phonemes. In transparent writing environment learners have to be able to differentiate very small units—phonemes, including 
their short and long forms—-from each other to connect them to their written form. Perceptual difficulties form thus an understandable bottleneck compromising typical reading acquisition.

This all means that attention to learners' readiness to learn to differentiate and store the sounds of letters forms a natural basis of basic reading acquisition, which can be observed in how children learn first the letter names and then the sounds. In Finnish the names given to letters provide effective cue of the sounds of the letters. This means that children who have learnt the names of letters without difficulties_-as most do-are most likely also not have to face any difficulties in learning the sounds of letters if instructed in an appropriate way. This is why it was no surprise that letter name knowledge showed up to be extremely effective predictor of reading acquisition among the JLD-participants as shown in Figure 1, which displays the predictive associations of developmental measures from the early pre-school years to reading acquisition among children who faced severe problems in learning to read. Practically all had difficulties in storing letter names and more reliably so than shown by difficulties observed using any other predictor. This has led to the adaptation of a very easy to use and practical measure to identify children who need help for getting sufficient preventive help. Such a prevention saves them from being affected by the experience of failure in learning to read when the large majority reaches perfect decoding skills in Finland. 


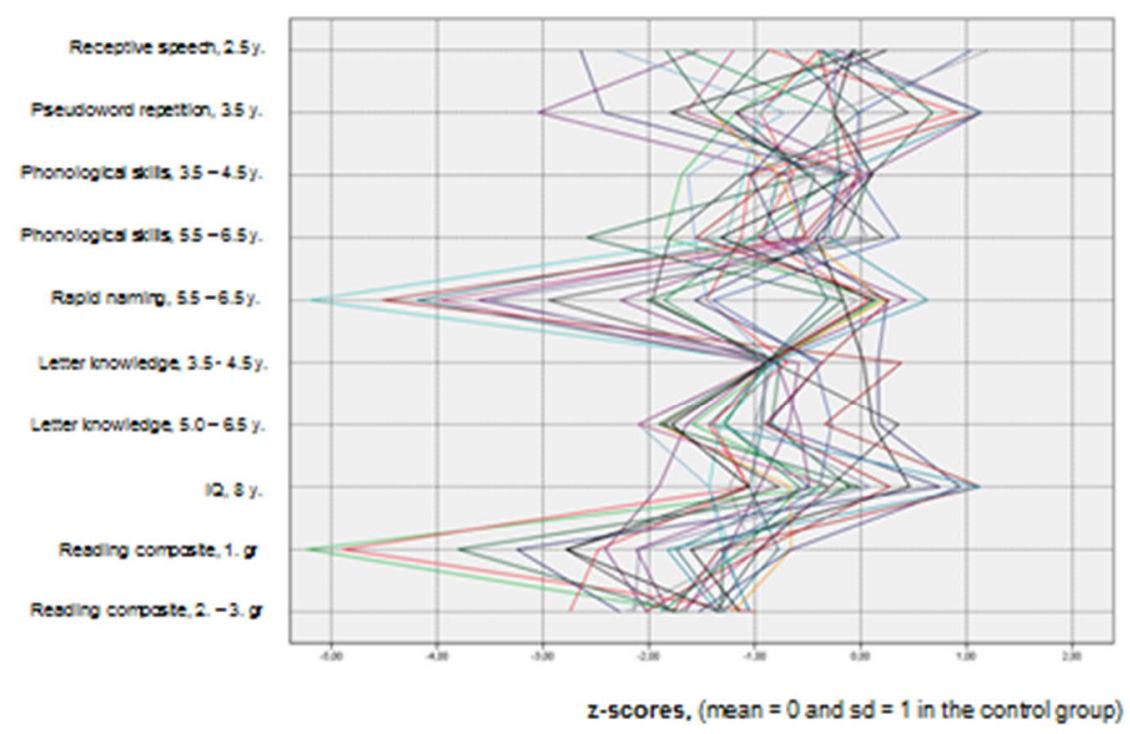

Individual profiles of all JLD children showing compromised reading at the end of the $2^{\text {nd }}$ grade

Figure 1. The JLD-follow-up from birth to school age of reading-related development: Individual profiles of the prediction measures of the children whose reading acquisition was most severely compromised (modified from "In search of a science-based application: A learning tool for reading acquisition,” by H. Lyytinen, J. Erskine, J. Kujala, E. Ojanen, and U. Richardson, 2009, Scandinavian Journal of Psychology, 50, p. 670).

\section{Intervention}

\subsection{Focus on specific skills}

Training and intervention methods for supporting reading development of struggling learners used in Finnish schools typically involve individual or small group training led by special education teachers. Such training is provided usually once or twice a week maximally for a period of one lesson (45 minutes) typically for limited period of time (one school term or such) but sometimes for much longer period.

\subsubsection{Training Phonological Skills}

The tendency is to provide the bulk of interventions at the early stages of school (first to third grade, i.e., 7 to 9 years) when children are taking their first steps in learning to read; learners 
with persistent and more severe deficits attend specific training also at the later stages of formal school with the same relatively low intensity rate (typically once a week face to face meetings with special education teachers or other experts). As of year 2009, $19 \%$ of first graders received parttime special education due to problems in reading and spelling development; at ninth grade the percentage was $1.5 \%$ (Kirjavainen, Pulkkinen, \& Jahnukainen, 2013).

The methods used in training and intervention studies typically involve tasks aimed at improving phonological awareness and phonological sensitivity (e.g., segment manipulations, perception usually with single sound/letter segments, syllables, or parts of compound words), auditory-visual connections (e.g., speech segments into written counterparts), reading and spelling exercises (e.g., repeated reading and shared reading sessions), and language games (syllables, rimes, phonemes). A mix of different tasks is often used to achieve significant improvements in reading skills.

In many of the intervention studies, training focuses on one linguistic/auditory factor as the center of training exercises. Due to the almost perfect ${ }^{1}$ consistency of letter-sound connections to both directions (reading and spelling) in Finnish, much of the training has focused on these connections. However, increasingly also syllables have been used as training units. In Finnish primary stress (with a lengthening of sound durations and higher fundamental frequency, tone) provides a strong perceptual cue to word beginnings. Cues to syllable segmentation also come from the system of lexical stress: The primary stress systematically falls on the first syllable and the secondary stress falls on every other syllable as a rule ${ }^{2}$; the last syllable is never being stressed. Because stress patterns are relatively systematic and predictable, thus facilitating syllable detection, syllables are used in school instruction as well as in intervention studies.

\footnotetext{
${ }^{1}$ The only exception for the letter-sound correspondence in Finnish is the fact that for the voiced velar nasal sound there is no unique letter that represents only that specific sound. This sound is represented by the letter $\langle\mathrm{n}>$ in front of the unvoiced velar stop sound $/ \mathrm{k} /$ and when the sound is geminated it is marked with the letter combination of $/ \mathrm{ng} /$.

${ }^{2}$ Secondary stress in Finnish takes into account the quantity of the syllable: it falls on heavy syllables instead of the proceeding light syllables in cases where the placement of the light syllable as a rule would be stressed.
} 


\subsubsection{Training Reading Skills}

Next, we provide a brief account of the findings of intervention studies with Finnish speaking dyslexic and/or poor readers at different stages of reading development. Several intervention studies have investigated the efficacy of training phonological (awareness) skills or phonological sensitivity in improving accuracy in reading and spelling for struggling readers. Poskiparta, Niemi \& Vauras (1999) conducted an intervention study with 7- to 8-year-old children attending the first year at school (20-minute intervention sessions in small groups, three to four times a week for altogether 47 sessions). The at-risk readers, whose phonological skills were assessed as being specifically poor at the beginning of the school year, were divided into three matched groups: One group attended phonological awareness intervention, the second received training in a normal special education group, and the third group received no extra support. The results show that the group who received specific training in phonological awareness skills using nursery rhymes performed significantly better than the other groups at word-recognition, spelling and listening comprehension. The children's skills were reassessed at the end of first grade and the intervention group's achieved gains remained. Thus, it seems that training in phonological awareness skills clearly benefits Finnish speaking at-risk readers. However, in the follow-up study, the same children's reading related skills were reassessed again in the third grade and the results showed that the children in the intervention group did not perform any better than the children in the control groups. It should be noted that the predictive value of phonological awareness skills on decoding skills in Finnish seems to diminish after children learn the basics of decoding skills (Holopainen, Ahonen, \& Lyytinen, 2001). Instead the predictive power of orthographic skills (letter knowledge) is very high in Finnish. It could be that once children learn Finnish letter sound correspondences they can utilize this knowledge to perform in phonological awareness tasks, thus reducing the predictive value of phonological awareness skills in reading skills. 
Ketonen (2010) conducted a phonological intervention study of six treatment-resistant dyslexic children taking part in the JLD-study who at the beginning of the intervention had familial risk for dyslexia and poor letter knowledge at preschool. The 20 -week intervention (one hour per week) focusing on phonological skills and letter sound knowledge was conducted at preschool or during the first year at school. The children's development was followed until the seventh grade (12-13 years). The study found that although phonological awareness skills and letter knowledge improved after the intervention period, this improvement was not reflected in children's reading and spelling skills. Thus, although the intervention was successful in improving certain reading related skills, this was not enough to significantly support children who had severe learning difficulties specifically in reading.

Apart from intervention studies focusing in improving reading accuracy, Finnish intervention studies have targeted reading speed (fluency). This is particularly relevant in the Finnish language context due to the fact that even struggling readers can often read accurately, but slowly. Heikkilä, Aro, Närhi, Westerholm, and Ahonen’s (2013) intervention study on fluency skills was conducted on poor readers from second and third grades (8- to 9-year-olds). Children were trained with a computerized repeated reading task for two to three weeks about 15 minutes at the time, three to five times a week. The training material included both short and long syllables. After the intervention, children's reading speed increased significantly for the trained syllables. The transfer effect to reading words including the syllables was significant only in reading words with infrequent syllables.

Huemer, Aro, Landerl, Lyytinen (2010) conducted a cross-over design intervention study in which poor readers from fourth to sixth grade (10- to 12-year-old children) participated in 10 training session over a two-week period in while the other group of poor readers waited to participate in the second part of the intervention. The children were trained to read a set of low frequency syllables (30 syllables) with altogether 50 presentations each during the intervention 
period. The results show that reading speed of the trained syllables increased after the intervention. Also, reading speed of pseudowords containing the trained syllables increased significantly. There was no transfer of the increased speed to reading a text that included only a very small portion (below $0.5 \%$ ) of the trained infrequent syllables, which suggests item-specific effects of the training. The intervention studies on fluency skills show that it seems to be possible to increase the speed of reading the specific trained items. The findings suggest that at a certain stage of skill development, poor reading fluency might be supported by practicing syllables as sublexical units larger than single phonemes/letters.

\subsubsection{Training Perceptual Skills}

Apart from phonological and repeated reading training, Finnish intervention studies of poor readers have also been conducted involving auditory perception tasks. The intervention study by Oksanen (2012) included auditory training, training on connecting auditory and visual stimuli, and reading and spelling training. All training tasks occurred in a separate period devoted to the intervention study. The training groups were further divided by the type of training stimuli used in the intervention: either speech or nonspeech stimuli with computerized tasks. The participating poor readers were third graders (9-year-olds). Children with matched reading skills from the same school classes served as non-training controls. The results of the different training periods showed that training with non-speech stimuli benefitted children in the auditory-visual connection tasks significantly more than the children who were trained with speech stimuli. Training with speech stimuli, on the other hand, improved reading accuracy skills significantly more than when children were trained with nonspeech stimuli.

Training mere auditory-visual matching skills has also been studied in the Finnish language context. The Audilex-computer program was used in the intervention by Kujala et al. (2001). Audilex uses various nonverbal sound patterns together with visual symbols (rectangles), the aim 
being to match presented sound patterns with the corresponding visually presented patterns of symbols. Seven-year-old poor readers participated in the seven-week intervention including 14 tenminutes training sessions once or twice per week. Both behavioral and brain measures were used in the assessments. The positive effects of training were shown on reading measures. Importantly, the results showed also observable plastic changes in the auditory cortex after training, indicated as increased MMNs as well as faster reaction times to the changes of speed.

\subsection{Effects of GraphoGame}

For over a decade now the computerized training and assessment environment, GraphoGame (GG); known as Ekapeli in Finnish), has been used in intervention studies that focus on connecting units of speech directly with corresponding written language units. (For a summary of results associated with GG, see Richardson \& Lyytinen, 2014). The rationale for the game environment originally came from the research findings that learners who struggle in reading find it difficult to learn the connections between speech sounds and letters. This led to the adaptation of a very easy to use and practical measure to identify children who need extra support to prevent being affected by failure in learning to read during the first months of reading instruction, when the very large majority reaches accurate reading skills. The game adapts to each individual player's skills by providing training content that is sufficiently challenging but at the same time provides content that even struggling learners succeed in finding correct correspondences between spoken and written items.

Following this failure-prevention logic, Mönkkönen et al. (2014) carried out a GraphoGame intervention study with preschool aged children (6- to 7-year-olds) who had poor letter sound knowledge at the end of the preschool prior entering school. A cross-over design was used in which children played first either GraphoGame during the first 6 weeks of the intervention for on average 3.5 hours altogether in short 10 to 15 minutes playing sessions, or similar game with math content 
for the same period of time. After six weeks, the groups switched to play the game that they had not played during the first intervention period. In addition, the study design included a matched group of children who did not participate in any intervention training sessions. The results show that even with such a short but relatively intensive training with GraphoGame children's letter knowledge as well as pseudoword reading skills improved significantly in comparison to the children playing the math game or those not participating in training.

A study conducted by Saine, Lerkkanen, Ahonen, Tolvanen, and Lyytinen (2011) followed children's development after a relatively long and intensive GraphoGame intervention period (28 weeks with 15 minutes training sessions with GraphoGame plus 30 minutes of regular reading support for four times a week). The study design included two control groups: matched level poor readers at the start of the first grade (7-year-olds) who received regular reading support similarly to the GraphoGame intervention group for 45 minutes at each training session but without the 15 minutes GraphoGame training. Second, the classmates of the intervention group children participated in the study as typically reading controls who did not need any extra support for learning to read. Children's reading skills were assessed immediately after the end of the intervention period as well as when they were on the third grade at school (9-year-olds). The results showed that the long and intensive training period with GraphoGame had significant effect on the poor readers reading skills in comparison to the children attending regular remedial support. Significantly, the GraphoGame intervention was sufficient to increase poor learners reading skills up to the level of their nonintervention mainstream peers when their reading skills were assessed almost two years after the intervention period. This finding seems very encouraging on the efficiency of training reading skills of poor readers in Finnish. It seems that in a language like Finnish with shallow orthography, training with matching speech sounds to written language units directly in intensive and motivating learning sessions is sufficient for significantly supporting poor learners reading skills. 
Interestingly GraphoGame has motivated a number of brain-related studies. For example, Brem et al. (2010) used several concomitant imaging methods to observe the associative learning occurring after a short (3-4 hours) playing time of GraphoGame and observed the results of learning in brain areas, including the so called Visual Word Form Area of the brain. Today these promising findings have motivated researchers in many countries to do similar intervention studies based on the success in Finland, where educational authorities have facilitated applications of the interventions. The website (www.lukimat.fi) supports both reading and math skills via Ekapeli and provides an information data base for teachers and parents to understand how to best support struggling learners. Today more than ten thousand Finnish children may play these learning games during one day after hundreds of thousands have benefited from this support after it has become freely available to learners via Internet since 2006.

\section{Discussion and Conclusion}

In the Finnish language context, learners have a relatively easy job in accessing the first important steps of learning to read. This is largely because the Finnish language has a very straightforward system in which there is one-to-one correspondence with speech sounds and letters in both reading and writing directions. However, struggling learners of the Finnish orthography find it difficult to learn even the simple system of these connections. It takes them significantly longer to learn letter-sound correspondences and this is reflected in the speed in which they learn how to combine units to make larger units such as syllables and words. In general, however, even individuals with dyslexia learn to decode accurately Finnish writing. Also, they may make spelling mistakes especially in reproducing the phonemic length accurately in writing. The fact that seems to be both a cause and consequence is that reading tends to stay slow. This is at least partly due to a compromised interest in reading for leisure, a practice which could help in automatizing decoding skills. 
The intervention methods used in Finland for supporting dyslexic and poor readers have been proven to be effective in supporting their reading accuracy and even speed of reading. Importantly, the Finnish language context facilitates identification of poor learners at the age before they start to learn to read. This makes it possible to provide preventive training which in turn is important for learners' motivation and learning careers. As with any severe learning difficulty the importance of early identification, appropriate content for training, and sufficiently intensive and long-lasting training support is urgently needed. As the intervention studies reviewed here indicate, providing an engaging learning environment — such as GraphoGame for individually adaptive training with endless opportunities to repeat the speech-sound connections and to increase the speed of these connections — can be the key for supporting reading development of poor learners. 


\section{References}

Aro, M. (in press). Learning to read Finnish. In L. Verhoeven \& C. Perfetti (Eds.) Reading acquisition across languages and writing systems: An international handbook. Cambridge University Press.

Brem, S., Bach, S., Kucian, K., Kujala, J. V., Guttorm, T. K., Martin, E., ... Richardson, U. (2010). Brain sensitivity to print emerges when children learn letter-speech sound correspondences. Proceedings of the National Academy of Sciences, 107, 7939-7944.

Guttorm, T., Leppänen, P., Hämäläinen, J., Eklund, K., \& Lyytinen, H. (2010). Newborn eventrelated potentials predict poorer pre-reading skills in children with dyslexia. Journal of Learning Disabilities, 43, 391-401.

Heikkilä, R., Aro, M., Närhi, V., Westerholm, J., \& Ahonen, T. (2013). Does training in syllable recognition improve reading speed? a computer-based trial with poor readers from second and third grade. Scientific Studies of Reading, 17, 398-414.

Holopainen, L., Ahonen, T., \& Lyytinen, H. (2001) Predicting delay in reading achievement in a highly transparent language. Journal of Learning Disabilities, 34, 401-413.

Huemer, S., Aro, M., Landerl, K., \& Lyytinen, H. (2010). Repeated reading of syllables among Finnish-speaking children with poor reading skills. Scientific Studies of Reading, 14, 317340.

Ketonen, R. (2010). Dysleksiariski oppimisen haasteena: Fonologisen tietoisuuden interventio ja lukemaan oppiminen. Jyväskylä studies in education, psychology and social research; 0075$4625 ; 404$.

Kirjavainen, T., Pulkkinen, J., \& Jahnukainen, M. (2013). Erityisopetuksen muutostrendit perusopetuksessa 2000-luvulla [The trends of change in special education after year 2000]. Valtiontalouden tarkastusvirasto [National Audit Office of Finland]. Retrieved January 25, 
2015 from http://www.vtv.fi/files/3564/Tyopaperi_Erityisopetuksen_muutostrendit_ perusopetuksesa_2000-luvulla.pdf

Kujala, T., Karma, K., Ceponiene, R., Belitz, S., Turkkila, P., Tervaniemi, M., \& Näätänen, R. 2001. Plastic neural changes and reading improvement caused by audiovisual training in reading-impaired children. Proceedings of the National Academy of Sciences, 98, 10509_ 10514

Leppänen, P. H. T., Hämäläinen, J. A., Salminen, H., Eklund, K., Guttorm, T., Lohvansuu, K., ... Lyytinen, H. (2010). Brain event-related potentials reveal atypical processing of sound frequency and the subsequent association with later literacy skills in children with familial dyslexia. Cortex, 46, 1362-1376.

Lyytinen, H., Erskine, J., Hämäläinen, J., Torppa, M., \& Ronimus, M. (2015). Dyslexia—Early Identification and Prevention: Highlights from the Jyväskylä Longitudinal Study of Dyslexia. Current Developmental Disorders Reports, 2, 330-338.

Lyytinen, H., Erskine, J., Kujala, J., Ojanen, E., \& Richardson, U. (2009). In search of a sciencebased application: A learning tool for reading acquisition. Scandinavian Journal of Psychology, 50, 668-675.

Malin, A., Sulkunen, S., \& Laine, K. (2013) PIAAC 2012. Kansainvälisen aikuistutkimuksen ensituloksia [PIAAC 2012. The survey of adult skills]. Helsinki: Opetus- ja kulttuuriministeriön julkaisuja, 2013:19.

Mönkkönen, A., Bach, S., Brem, S., Erskine, J., Kujala, J., Willems, G., \& Richardson, U. (2014). Technology-enhanced training of basic decoding skills in preschool age children. Manuscript in preparation.

Oksanen, A.-M. (2012) Auditiivisen ja kielellisen harjoittelun vaikutus kolmannella luokalla olevien heikkojen lukijoiden lukutaitoon. Jyväskylä Studies in Education, Psychology and Social Research, 443. 
Poskiparta, E., Niemi, P. \& Vauras, M. (1999). Who benefits from training in linguistic awareness in the first grade, and what components show training effects? Journal of Learning Disabilities, 32, 437-446.

Richardson, U., Leppänen, P. H. T., Leiwo, M., \& Lyytinen, H. (2003). Speech perception of infants with high familial risk for dyslexia differ at the age of 6 months. Developmental Neuropsychology, 23, 385-397.

Richardson, U., \& Lyytinen, H. (2014). The GraphoGame method: The theoretical and methodological background of the technology-enhanced learning environment for learning to read. Human Technology, 10, pp. 39-60.

Saine, N. L., Lerkkanen, M.-K., Ahonen, T., Tolvanen, A., \& Lyytinen, H. (2011). Computerassisted remedial reading intervention for school beginners at-risk for reading disability. Child Development, 82, 1013-1028.

Official Statistics of Finland (2014). Special education. Share of students having received special support diminished [e-publication]. Helsinki: Statistics Finland. Retrieved January 25, 2015 from http://www.tilastokeskus.fi/til/erop/2013/erop_2013_2014-06-12_tie_001_en.html 